\title{
Retraction Note: Image simulation of coastal climate and badminton sports based on SAR remote sensing images
}

\author{
Qiuru Chen ${ }^{1}$
}

Published online: 15 November 2021

C) Saudi Society for Geosciences 2021

Retraction Note to: Arabian Journal of Geosciences (2021) 14: 987

https://doi.org/10.1007/s12517-021-07347-1

The Editor-in-Chief and the Publisher have retracted this article because the content of this article is nonsensical. The peer review process was not carried out in accordance with the Publisher's peer review policy. The author has not responded to correspondence regarding this retraction.

The original article can be found online at https://doi.org/10.1007/ s12517-021-07347-1.

Qiuru Chen

qr906293455@163.com

1 Department of Physical Education, Suzhou University, Suzhou 234000, Anhui, China 